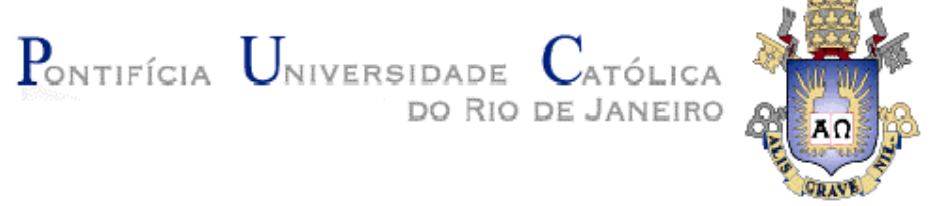

Rita R V Peixoto Migliora

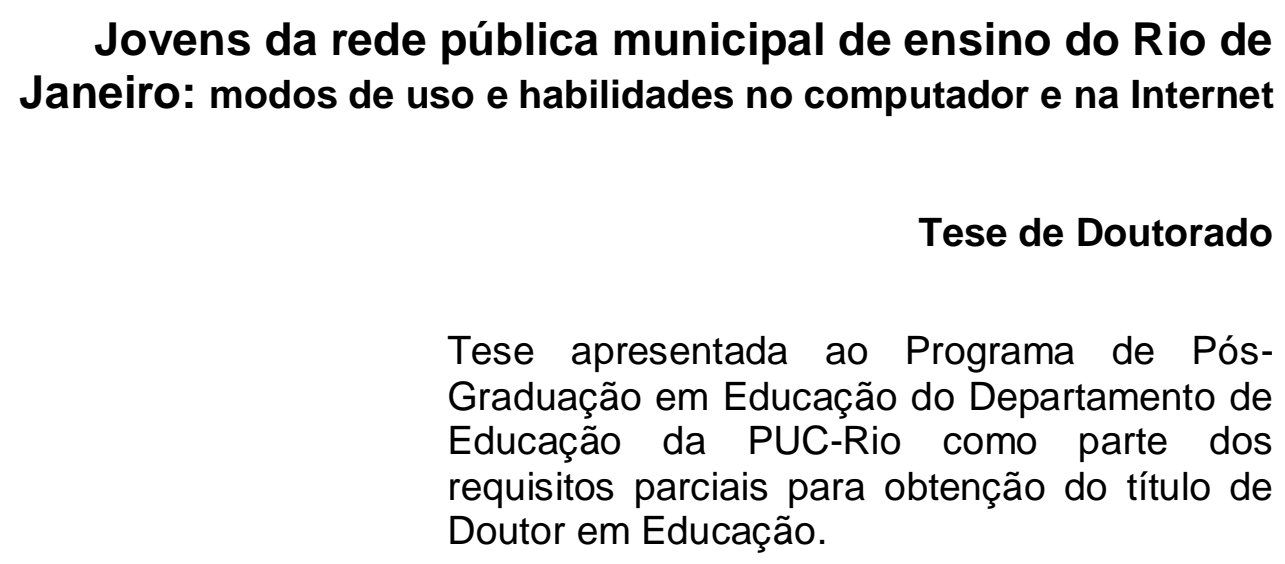

Orientador: Prof ${ }^{\mathrm{a}}$ Rosália Maria Duarte Co-orientadora: Prof ${ }^{a}$ Sibele Cazelli - MAST 


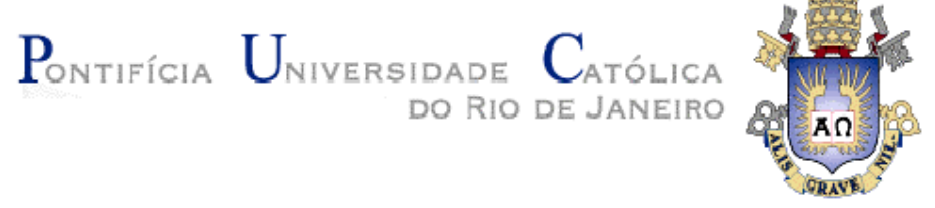

Rita R V Peixoto Migliora

\title{
Jovens da rede pública municipal de ensino do Rio de Janeiro: modos de uso e habilidades no computador e na Internet
}

Tese apresentada como requisito parcial para obtenção do título de Doutor pelo Programa de Pós-Graduação em Educação do Departamento de Educação do Centro de Teologia e Ciências Humanas da PUC-Rio. Aprovada pela Comissão Examinadora abaixo assinada.

\author{
Prof ${ }^{a}$ Rosália Maria Duarte \\ Orientadora \\ Departamento de Educação - PUC-Rio \\ Prof \\ Co-orientadora \\ MAST \\ Profa Alicia Maria Catalano de Bonamino \\ Departamento de Educação - PUC-Rio \\ Prof ${ }^{a}$. Maria Apparecida Campos Mamede Neves \\ Departamento de Educação - PUC-Rio \\ Prof ${ }^{a}$ Guaracira Gouvêa de Souza \\ UNIRIO
}

Prof. Alexandre Fernandes Barbosa UFMG

Prof ${ }^{a}$ Denise Portinari Coordenadora Setorial do Centro de Teologia e Ciências Humanas

Rio de Janeiro, 01 de abril de 2013. 
Todos os direitos reservados. É proibida a reprodução total ou parcial do trabalho sem autorização da universidade, da autora e do orientador.

\section{Rita R V Peixoto Migliora}

Graduou-se em Pedagogia, na Pontifícia Universidade Católica do Rio de Janeiro (PUC-Rio), em 2003. Mestrado em Educação pela Pontifícia Universidade Católica do Rio de Janeiro (PUC-Rio), em 2007. Faz parte do Grupo de Pesquisa em Educação e Mídia (GRUPEM), desde 2001, coordenado pela Professora Rosália Duarte. Tem experiência na área de Educação, com ênfase em Mídia e Educação, atuando principalmente nos seguintes temas: cultura, recepção, crianças e jovens, mídias, significação e habilidades educacionais.

Ficha Catalográfica

Migliora, Rita Rezende Vieira P.

Jovens da rede pública municipal de ensino do Rio de Janeiro: modos de usos e habilidades no computador e na Internet / Rita Rezende Vieira P. Migliora; orientadora: Rosália Maria Duarte, co-orientadora: Sibele Cazelli. - 2013. 257 f. : il. ; $30 \mathrm{~cm}$

Tese (doutorado)-Pontifícia Universidade Católica do Rio de Janeiro, Departamento de Educação, 2013.

Inclui bibliografia

1. Educação - Teses. 2. Jovens. 3. Modos de uso de mídias. 4. Habilidades de uso do computador. 5. Habilidades educacionais. I. Duarte, Rosália Maria. II. Cazelli, Sibele. III. Pontifícia Universidade Católica do Rio de Janeiro. Departamento de Educação. IV. Título.

CDD: 370 


\section{Agradecimentos}

A minha orientadora e amiga Rosália por todo apoio, carinho, por ter compartilhado cada momento desta pesquisa comigo.

A minha co-orientadora Sibele por sua disponibilidade e tranquilidade.

A todos do GRUPEM, Cris, Adriana, Andrea, Bia, Cintia, Ilana, Luciana, Lu, Marcus, Raquel, Winston que tanto me ajudaram em todas as fases da pesquisa.

A Alicia pela acolhida generosa e os conselhos sábios nos meus momentos de angústia .

As minhas irmãs - Aline e Janice por sempre terem acreditado em mim, pelas discussões sobre o método e ajuda inestimável que sempre me deram.

Ao Lig pelo seu companheirismo e ajuda na breve revisão.

Aos meus amores Clara, Ana e Guilherme por terem sido compreensivos, carinhosos e por terem comprado essa ideia comigo.

Aos meus pais por tudo sempre.

Aos jovens, principalmente àqueles que concederam as entrevistasque foram tão generosos, e as escolas que participaram desta pesquisa, tornando-a possível.

A Secretaria Municipal de Educação por autorizar nossa pesquisa em suas escolas.

A Capes e ao CNPq por financiarem o meu Doutorado.

E a FAPERJ por ter financiado a pesquisa Juventude e Mídia. 


\section{Resumo}

Migliora, Rita Rezende V. P.; Duarte, Rosália. Jovens da Rede Pública Municipal de Ensino do Rio de Janeiro: modos de usos e habilidades no computador e na internet. Rio de Janeiro, 2013. 257p. Tese de doutorado - Departamento de Educação, Pontifícia Universidade Católica do Rio de Janeiro.

São os jovens que convivem de modo contínuo e crescente com novos conteúdos, usos e contextos de interação através das novas mídias, sendo assim é importante investigar mais sobre esses usos e suas possíveis relações entre eles e os processos educativos Os objetivos deste estudo, que tem como base a Pesquisa Juventude e Mídia, estão relacionados a identificação, descrição e análise dos modos de uso de mídias digitais, especialmente da internet, construídos por estudantes do $9^{\circ}$ ano do ensino fundamental da rede pública municipal do Rio de Janeiro, em contexto escolar e no seu tempo livre e as habilidades desenvolvidas por estes jovens a partir dos usos.

A realização desse estudo envolveu a construção e aplicação de questionários junto a 3705 alunos do $9^{\circ}$ ano do Ensino Fundamental em uma amostra de 39 escolas. A análise dos dados foi baseada na aplicação de oito modelos de regressão linear. Os resultados indicam há uma correlação negativa entre a defasagem idade/série e habilidades (quanto maior o número de anos de atraso em relação à idade esperada menor a probabilidade de se declarar habilidoso), que pode estar relacionada ao efeito da baixa autoestima. Por outro lado há uma correlação positiva entre o desenvolvimento de habilidades e a presença, no âmbito doméstico, de mídias e livros, assim como a prática de atividades culturais cultivadas (frequência a museus, centros culturais, cinema, teatro, shows etc.) que sugere a necessidade de redução da desigualdade social, o que tornaria tais recursos acessíveis a todos. Nossos resultados sugerem que o ganho mais significativo no uso do computador e da Internet entre os jovens pesquisados se dá no âmbito da sociabilidade, entendida como transmissão de conhecimentos, normas e valores entre pares.

\section{Palavras-chave:}

Jovens; modos de uso de mídias; habilidades de uso do computador; habilidades educacionais. 


\section{Abstract}

Migliora, Rita Rezende V. P.; Duarte, Rosália. (Advisor). Young People of the public Municipal schools of Rio de Janeiro: digital media uses and computer skills. Rio de Janeiro, 2013. 257p. Thesis - Departamento de Educação, Pontifícia Universidade Católica do Rio de Janeiro.

The young adults are the ones who interact on a continuous and growing basis with the new contents, uses and interaction contexts through the new media. Therefore, it is important to further investigate these uses and their possible relations between them and with the education processes. The purpose of this study, which has as its basis the Research Youth and Media, are related to the identification, description and analysis of the ways of use of digital media, specially the Internet, developed by students of the 9th grade of the fundamental cycle of the public Municipal schools of Rio de Janeiro in the school context and in their free time and the abilities developed by these young adults as a result of these uses.

Carrying out this study involved the development and application of questionnaires to 3,705 students of the 9th grade of the fundamental cycle in a sample of 39 schools. The data analysis was based on the application of eight linear regression models The results show a negative correlation between the gap age/grade and abilities (the higher the number of years of delay as compared to the expected age the lower the probability of the student declaring him/herself skillful)., what may be related to the effect of low self esteem. On the other hand, there is a positive correlation between the development of abilities and the presence in the domestic environment of media and books, as well as the engagement in cultural activities (visits to museums, cultural centers, movie theatres, plays, shows etc) what suggests the need of reducing the social differences, what would make these resources available to all. Our results suggest that the most significant gain resulting from the use of computer and internet among the young adults subject of the research is verified in their sociability, understood as transmission of knowledge, rules and value between the pairs.

\section{Key-words:}

Youth; media use; computer abilities; educational abilities. 


\section{Sumário}

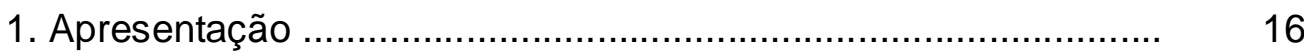

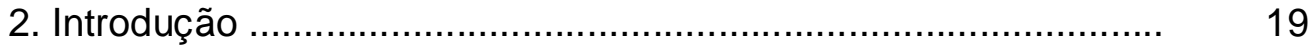

3. Algumas pesquisas sobre crianças e jovens e sua relação com

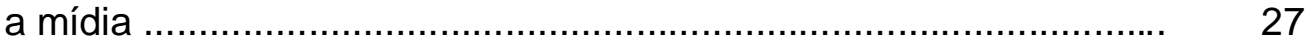

4. Pesquisa Juventude e Mídia ............................................... 40

5. Metodologia ................................................................ 46

5.1. Descrição do presente estudo ........................................... 46

5.2. Descrição do instrumento de pesquisa ................................. 51

5.2.1. Conceitos operacionalizados no questionário do aluno ......... 51

5.3. Modelos da análise ........................................................ 60

5.3.1. Criação das escalas ................................................... 60

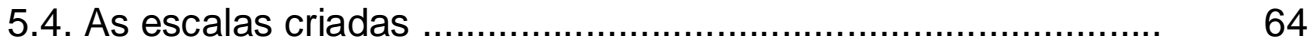

5.4.1. Escalas de frequência de uso do computador e da Internet pelo aluno ................................................................................. 65

5.4.2. Escala sobre a habilidade percebida pelo aluno no uso do computador e da internet .......................................................... 66

5.4.3. Escala de frequência de uso social do computador e da internet pelo aluno ............................................................ 68

5.4.4. Escala de frequência de uso tecnológico do computador e da internet pelo jovem

5.4.5. Escala de frequência de uso educacional do computador e 
da internet pelo aluno

5.4.6. Escala de habilidade percebida pelo aluno no uso social do computador

5.4.7. Escala de habilidade percebida pelo aluno no uso tecnológico do computador e da internet

5.4.8. Escala de habilidade percebida pelo aluno no uso educacional do computador e da internet

5.4.9. Escala frequência de participação em atividades culturais cultivadas 74

5.4.10. Escala frequência de participação em atividades esportivas 74

5.4.11. Escala frequência de participação em atividades de lazer .. 74

5.4.12. Escala frequência de uso de celular 74

5.4.13. Escala frequência de participação em atividades religiosas

5.4.14. Escala de frequência com que assiste a determinados programas na TV 75

5.4.15. Escala de disponibilidade de mídia na casa do aluno

5.4.16. Escala de disponibilidade de jornais/revistas de informação geral na casa do aluno

5.4.17. Escala de disponibilidade de revistas de divulgação científica/ livros de literatura na casa do aluno

5.4.18. Escala de posse de bens da família do aluno

5.5. Regressão linear múltipla

6. Análise dos dados

6.1. Descrição da amostra 85

6.1.1. Frequência de uso do computador

6.1.2. Declaração de habilidade no uso do computador e da Internet

109

6.1.3. Outras freqüências

6.2. Modelos de regressão linear: variáveis dependentes _ escalas de frequência de uso do computador e habilidades no uso do computador e da Internet ......

6.3. Modelos de regressão linear: variáveis dependentes _ escalas de frequência de uso educacional, social e tecnológico do 
computador e da internet

136

6.3.1. Frequência de uso educacional do computador e da Internet 137

6.3.2. Frequência de uso tecnológico do computador e da Internet 141

6.3.3. Uso social do computador e da Internet ............................... 146

6.3.4. Habilidade educacional no uso do computador e da Internet 152

6.3.5. Hablidade tecnológica no uso do computador e da Internet .. 162

6.3.6. Habilidade social no uso do computador e da Internet .......... 168

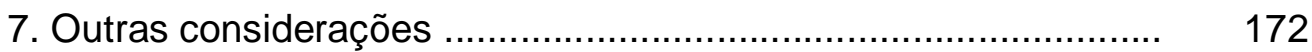

7.1. Uso e habilidade pela lente da sociabilidade ........................... 172

7.2. Modos de ver tevê influenciando a habilidade no uso da

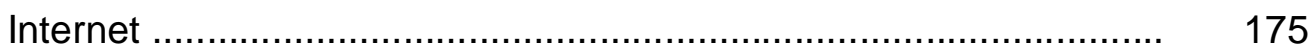

7.3. Aprendizagem na Internet ................................................. 178

8. Considerações finais ............................................................... 185

9. Referências Bibliográficas ……………………………….... 193

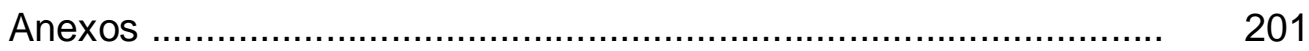




\section{Lista de Figuras}

Figura 1 - Desenho da pesquisa .............................................. $\quad 15$

Gráfico 1- Distribuição dos jovens por idade .................................. $\quad 85$

Gráfico 2 - Distribuição dos jovens por cor/raça ........................... $\quad 86$

Gráfico 3 - Percentagem de pais por nível de escolaridade ........... $\quad 86$

Gráfico 4 - Percentagem dos jovens por tempo de uso do

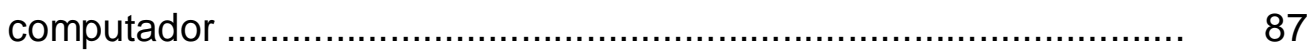

Gráfico 5 - Percentagem de alunos que usam computador na escola

Gráfico 6 - Percentagem de alunos que usam computador em lan houses, casa de amigos e em casa ................................................ 88 Gráfico 7 - Cruzamento entre sexo e frequência de uso do computador na escola

Gráfico 8 - Cruzamento entre sexo e frequência de uso do computador em casa

Gráfico 9 - Cruzamento entre sexo e frequência de uso do computador em locais públicos

Gráfico 10 - Cruzamento entre sexo e frequência de uso para jogar jogos instalados ou em CD's e para jogar jogos online.

Gráfico 11 - Crosstab entre sexo e a frequência de uso para postar fotos e baixar fotos da câmera digital

Gráfico 12 - Distribuição dos jovens por frequência de uso para jogar jogos

Gráfico 13 - Distribuição dos alunos por frequência de uso para jogar jogos online

Gráfico 14 - Distribuição dos jovens por frequência de uso para baixar fotos de câmera digital

Gráfico 15 -Distribuição dos jovens por frequência de uso para baixar música

Gráfico 16 - Distribuição dos jovens por frequência de uso para assistir filmes e clipes online 
postar música

Gráfico 18 - Distribuição dos jovens por frequência de uso para postar fotos

Gráfico 19 - Distribuição percentual dos jovens por frequência de uso para frequentar sites de rede social e para comunicação pelo Skype e outros

Gráfico 20 - Distribuição dos jovens por frequência de uso para procurar na Internet informações

Gráfico 21 - Distribuição dos jovens por frequência de uso para participar de blogs

Gráfico 22 - Distribuição dos jovens por frequência de uso para escrever textos pessoais

Gráfico 23 - Distribuição dos jovens por frequência de uso para pesquisar coisas novas 102 Gráfico 24 - Distribuição dos jovens por frequência de uso para usar programas gráficos 102 Gráfico 25 - Distribuição dos jovens por frequência de uso para usar programas educacionais 103 Gráfico 26 - Distribuição dos jovens por frequência de uso para baixar ou ler livros digitais 103 Gráfico 27 - Distribuição dos jovens por frequência de uso para ler ou mandar e-mails

Gráfico 28 - Distribuição dos jovens por frequência de uso para escrever trabalhos para a escola

Gráfico 29 - Distribuição dos jovens por frequência de uso para copiar e colar textos da Internet em trabalhos escolares .

Gráfico 30 - Distribuição dos jovens da habilidade declarada de gravar CD ou DVD

Gráfico 31 - Distribuição dos jovens da habilidade declarada em copiar CD ou DVD

Gráfico 32 - Distribuição dos jovens da habilidade declarada para usar programas para eliminar vírus do computador Gráfico 33 - Distribuição dos jovens da habilidade declarada para 
editar fotografias ou outras imagens

Gráfico 34 - Distribuição dos jovens da habilidade declarada para mover arquivos de um lugar para outro dentro do computador

Gráfico 35 - Distribuição dos jovens da habilidade declarada para baixar arquivos ou programas da Internet

Gráfico 36 - Distribuição dos jovens da habilidade declarada para editar música

Gráfico 37 - Distribuição dos jovens da habilidade declarada para editar vídeos

Gráfico 38 - Distribuição dos jovens da habilidade declarada para construir páginas na web

Gráfico 39 - Distribuição dos jovens da habilidade declarada para fazer várias tarefas ao mesmo tempo

Gráfico 40 - Distribuição dos jovens da habilidade declarada para instalar periféricos

Gráfico 41 - Percentagem de jovens de acordo com a posse de mídia em casa

Gráfico 42 - Distribuição dos alunos da escala de percepção de violência

Gráfico 43 - Distribuição dos jovens na escala de uso do computador e da Internet

127

Gráfico 44 - Distribuição dos jovens na escala de percepção da habilidade no uso do computador e da Internet

Gráfico 45 -Percentagem dos jovens que possuem computador, Internet banda larga e acesso à Internet discado

Gráfico 46 - Distribuição percentual da escala de disponibilidade de mídia em casa 135

Gráfico 47 - Cruzamento do uso educacional por idade

Gráfico 48 - Distribuição percentual dos jovens pelas práticas de assistir TV

Gráfico 49 - Distribuição dos jovens pela escala de uso tecnológico do computador e da Internet

Gráfico 50 - Distribuição dos jovens pela escala de uso social do 
computador e da Internet

Gráfico 51 - Distribuição dos jovens pela escala de percepção da

habilidade educacional no uso do computador e da Internet

152

Gráfico 52 - Cruzamento da escala de percepção da habilidade educacional por idade

157

Gráfico 53 - Distribuição dos jovens pela escala de uso

educacional do computador e da Internet

Gráfico 54 - Distribuição dos jovens pela escala de uso do celular ..

Gráfico 55 - Correlação entre a frequência de uso educacional por

percepção da habilidade educacional

Gráfico 56 - Distribuição dos jovens pela escala de habilidade

tecnológica no uso do computador e da Internet

162

Gráfico 57 - Correlação entre a frequência de posse de bens por

percepção da habilidade tecnológica por raça

166

Gráfico 58 - Distribuição dos jovens pela escala de habilidade

social no uso do computador e da Internet

\section{Lista de Quadros}

Quadro 1 - Quadro resumo dos alunos entrevistados online .......... 50

Quadro 2 - Quadro resumo dos conceitos e suas classificações ... 53

Quadro 3 - Modos de uso e suas especificações .......................... 54

Quadro 4 - Habilidades no uso do computador e da internet e suas especificações ............................................................... 56

Quadro 5 - Consumo Cultural e suas especificações .................... 58

Quadro 6 - Posse de bens e suas especificações ......................... 59

Quadro 7 - Perfil dos alunos e suas especificações ....................... $\quad 59$

Quadro 8 - Descrição das variáveis utilizadas no modelo de regressão 


\section{Lista de Tabelas}

Tabela 1 - Coeficiente de escalonabilidade ...................................... 63

Tabela 2 - Coeficientes de confiabilidade Rho de Mokken .............. 63

Tabela 3 - Propriedades dos itens da escala frequência de uso do computador

Tabela 4 - Propriedades da escala habilidade no uso do computador

Tabela 5 - Propriedades da escala de frequência de uso social do computador

Tabela 6 - Propriedade da escala de frequência de uso tecnológico do computador e da internet

Tabela 7 - Propriedades da escala de frequência de uso educacional do computador e da internet

Tabela 8 - Propriedades da escala de habilidade no uso social do computador

Tabela 9 - Propriedades da escala habilidade no uso tecnológico do computador e da internet

Tabela 10 - Propriedades da escala habilidade no uso educacional do computador e da internet

Tabela 11 - Exemplo de sumário de um modelo de regressão ........

Tabela 12 - Exemplo de tabela de coeficientes de um modelo de regressão

Tabela 13 - Atividades menos frequentes realizadas pelos jovens com percentagem das respostas dos níveis mais baixos e a média dos itens

Tabela 14 - Atividades mais frequentes realizadas pelos jovens com percentagem das respostas dos níveis mais altos e a média dos itens

Tabela 15 - Atividades em que os jovens se declararam menos hábeis com percentagem das respostas dos níveis mais baixos e 
a média dos itens

Tabela 16 - Atividades em que os jovens se declararam mais habilitados no uso do computador e da internet com percentagem das respostas dos níveis mais altos e a média dos itens

Tabela 17 - Práticas culturais queaso jovens declararam fazer com mais frequência com percentagem das respostas nos níveis mais altos e a média dos itens

Tabela 18 - Práticas culturais que os jovens declararam fazer com menos frequência com percentagem das respostas nos níveis mais baixos e a média dos itens

Tabela 19 - Modelo de regressão linear de frequência de uso do computador

Tabela 20 - Modelo de regressão linear da habilidade declarada no uso do computador

Tabela 21 - Modelo de regressão linear da frequência de uso educacional do computador e da Internet

Tabela 22 - Modelo de regressão linear da frequência de uso tecnológico do computador e da Internet

Tabela 23 - Modelo de regressão linear da frequência de uso social do computador e da Internet

Tabela 24 - Modelo de regressão linear da percepção da habilidade educacional no uso do computador e da Internet

Tabela 25 - Modelo de regressão linear da percepção da habilidade tecnológica no uso do computador e da Internet

Tabela 26 - Modelo de regressão linear da percepção da habilidade social no uso do computador e da Internet 